\title{
A FORMAÇÃO DE LEITORES LITERÁRIOS NA ERA DA SUA SACRALIDADE: SERIA O SAGRADO O ELEMENTO INTENSIFICADOR QUE EXPLICA O APREÇO DESMESURADO PELOS BEST-SELLERS SERIADOS?
}

Jaime dos Reis Sant'Anna

\begin{abstract}
RESUMO
$\mathrm{O}$ artigo discute o grande apreço por best-sellers seriados, como Harry Potter ou A Saga Crepúsculo e a viabilidade ou não de seu uso para formar leitores na escola; por fim, sugere que o sagrado é o elemento intensificador que explica a apreciação desmesurada por essas obras e aponta a necessidade de os professores debaterem esse tema com os seus alunos.
\end{abstract}

PALAVRAS-CHAVE: formação de leitor; literatura de massa; sagrado

\section{Introdução}

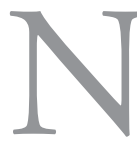

esse artigo, pretendemos dar continuidade ao debate acerca de um tema que vem sendo constantemente discutido, mas que ainda não se esgotou. Trata-se das possíveis estratégias a serem adotadas pelo professor de Língua Portuguesa com vistas à formação de leitores literários no Ensino Básico, especialmente no Ensino Fundamental (Anos Finais) e Ensino Médio. Para nortear o desenvolvimento das reflexóes sobre o assunto, propomos abordá-lo a partir do enfrentamento de algumas questóes que costumam ser apresentadas pelos alunos de Licenciatura em Letras e pelos docentes de língua materna nos cursos de formação continuada: no que concerne à formação de leitores literários, podemos optar pela leitura de obras procedentes da 
literatura trivial ou de massa, sobretudo dos best-sellers seriados? Ou devemos utilizar tão somente a literatura canônica, tendo em vista o papel da escola como responsável pela difusão de obras consagradas pelo tempo? Ou, ainda, podemos alternar a leitura de obras da literatura canônica com obras oriundas da chamada literatura trivial ou de massa, considerando-se o novo perfil de leitores que se configura no século XXI?

Depois de buscar algumas possíveis respostas para essas questóes - e considerando a natureza das obras que representam a literatura de massa e o modo como alguns docentes e até pesquisadores têm sucumbido aos apelos da indústria cultural que já atingem parte considerável do alunado do Ensino Básico -, propomos analisar as razóes que possam explicar o apego juvenil a esses best-sellers seriados, a partir de um recorte específico: seria a retomada do sagrado em diversas esferas culturais do mundo atual o elemento intensificador do interesse desmesurado por tais coleções?

O objetivo, portanto, é discutir a viabilidade ou não da utilização dos best-sellers seriados como ferramentas para a formação de leitores literários na escola e apontar a maneira como as novas representaçóes do sagrado nesse tipo de literatura refletem o Zeitgeist da sociedade contemporânea. Dessa forma, com ambas as discussóes, pretendemos apresentar um instrumental teórico-metodológico que contribua para proporcionar ao professor de Língua Portuguesa a autonomia intelectual necessária para decidir sobre suas práticas docentes no trabalho de formação de leitores literários críticos.

\section{Entre trilhas e trincheiras: a literatura de massa nas escolas}

Algumas preocupações justificam empreender tal discussão. Em primeiro lugar, o acirramento do paradoxo cada vez mais comum nas escolas e que deve movimentar as reflexóes acerca das políticas pedagógicas quanto à leitura literária de adolescentes no Ensino Básico: uma parcela nada desprezível do alunado lê compulsivamente centenas e milhares de páginas da literatura de massa, mas se mostra resistente à leitura das obras pertencentes ao cânone literário nacional ou universal. Em outros termos, enquanto se percebe certo desconforto com a literatura canônica presente nos programas de Língua Portuguesa, repudiando-se autores como José de Alencar, Machado de Assis, Mário de Andrade e Guimarães Rosa, entre 
outros, o mesmo não ocorre com a leitura de autores que representam a literatura de massa.

Entre 2013 e 2015, fizemos alguns questionamentos junto ao alunado do Ensino Fundamental (Anos Finais) de escolas públicas da região metropolitana de Londrina-PR, como parte das estratégias de execução do Projeto de Pesquisa intitulado "Ideologia e literatura juvenil brasileira contemporânea: contribuição para a formação do leitor literário crítico no Ensino Básico”, desenvolvido no âmbito da Universidade Estadual de Londrina (UEL).

Os resultados dos primeiros levantamentos revelam que, entre os estudantes que têm algum hábito regular de leitura literária, mais de $70 \%$ afirmam o apreço pela literatura trivial. Dessa literatura, a preferência repousa, sobretudo, nos best-sellers seriados, quer sejam "os mais antigos" - como As crônicas de Nárnia, de Clive Staples Lewis, publicados entre 1949 e 1954; e O senhor dos anéis, de John Ronald Reuel Tolkien, publicados entre 1954 e 1955 -, quer sejam "os menos antigos" - como Harry Potter, de Joanne K. Rowling, publicados entre 1997-2007; e Crepúsculo, de Stephenie Meyer, publicados entre 2005-2008; e até "os da 'nossa época', professor" - como a série Percy Jackson \& os Olimpianos, de Rick Russel Riordan, publicados entre 2005-2009; e a série Jogos vorazes, de Suzanne Collins, publicados entre 2008-2010. A lista inclui até mesmo A culpa é das estrelas, de John Green, de 2012, "que [ainda] não é seriado, professor, mas está bombando”.

Entre educadores, duas trincheiras também se erguem. De um lado, os que entendem que essas leituras pouco ou nada contribuem para a formação de leitores críticos, pois elas geram alienação mantenedora do status quo, alimentam conformismo perante uma sociedade conservadora, atendem somente às demandas da chamada indústria cultural, produzindo um esvaziamento da complexidade estética da obra literária e suas funçóes transformadoras. De outro lado, os que festejam todos os tipos de leitura literária, seja como forma de incentivo ao suposto protagonismo libertário e democrático do alunado quando de suas escolhas pessoais, seja como valorização do prazer no ato de ler demonstrado pelos leitores, seja como porta de entrada para a leitura de obras canônicas da literatura, seja pela oportunidade de o professor aproximar-se das representaçóes da cultura de massa que permeiam o universo adolescente.

Antoine Compagnon registrou a materialização desse conflito ao observar a disposição dos livros nas prateleiras das livrarias: "de um lado, a estante 
Literatura e, do outro, a estante Ficção; de um lado, os livros para escola, e de outro, os livros para o lazer, como se a Literatura fosse a ficção entediante, e a Ficção, a literatura divertida" (COMPAGNON, 2001, p. 30). O quadro dicotômico formado pelos livros canônicos e os da literatura de massa revela a chatice e a diversão que ambos os grupos distintivamente representam para o público que se encontra fora dos muros da Escola e é mais um dos desafios a ocupar o já sobrecarregado balaio de preocupaçóes do professor de Língua Portuguesa.

Por isso, a discussão visa a estimular o debate acerca do posicionamento da Escola - e do professor, em particular, tendo em vista seu papel mediador no processo de formação de leitores - perante a situação paradoxal que se apresenta entre adolescentes do mundo inteiro e com reflexos nos adolescentes do Brasil. Uma primeira atitude docente "simpática" perante os alunos é render-se às pressóes mercadológicas e aliar-se à literatura de massa ou trivial, e em especial aos best-sellers seriados repletos de vampiros, bruxos, duendes, faunos e outras figuras fantasiosas, com os quais os adolescentes parecem identificar-se; e a partir daí, buscar estratégias que possibilitem algum tipo de criticismo no processo formativo desses leitores e investir na construção de pontes que permitam o trânsito para a literatura canônica. A motivação seria o espírito conformista, representado mais ou menos no dito popular "se não pode com eles, junte-se a eles".

Para Joachim, tal postura garantiria ao aluno a liberdade de ler com intensidade aquilo que vai torná-lo um membro ativo da sociedade, enquanto ao professor caberia o papel de monitor conselheiro. Em outros termos, "a atitude do professor seria a de sugerir e acolher iniciativas, de lançar e de receber desafios, de saber monitorar sem se impor, de saber aprender dos outros, seja quem for, de deixar ser o ser, num clima descontraído e empático" (JOACHIM, 2010, p. 16).

Na perspectiva de Chiappini, entretanto, essa é uma atitude pseudolibertária, mais próxima da tolerância permissiva que da participação democrática do alunado. Trata-se de uma postura que - além de alimentar demasiada condescendência para com os produtos da indústria cultural, que já possui seu aparato midiático de persuasão do consumidor - infere certo preconceito contra a possibilidade de as classes sociais menos favorecidas desfrutarem literatura de alta qualidade estética, representada nas obras de autores canônicos. 
Para ela, a alternativa é "assumir os textos literários canônicos como o material com o qual se trabalha a formação de leitores, explicando aos alunos o que significam e para que servem, sem deixar de discutir com a academia sua atualidade" (CHIAPPINI, 2005, p. 251).

Em vista disso, uma segunda atitude - e que contraria o gosto comum disseminado entre adolescentes - é o professor de língua materna resistir ao espírito de época, negar a relevância da literatura de massa para o trabalho de formação de leitores críticos, colocando em plano secundário a sua leitura, preferencialmente para fora dos muros da Escola; e a partir dá, insistir no papel da Escola como agente autônomo que, não obstante venha a causar o desconforto desses mesmos adolescentes, deve investir na formação de leitores literários por meio da leitura de textos canônicos ou de literatura atual, quer seja nacional, quer seja universal, cujo valor vem senso atestado por instâncias de legitimação confiáveis. A motivação, nesse caso, seria o espírito de contestação e insubmissão ao mercado editorial que estabelece as regras do gosto incutido pela indústria cultural.

Todavia, vale alertar que restringir a discussão acerca da literatura de massa no âmbito dos interesses puramente educacionais resultará estéril se não atentarmos para o fato de estarmos lidando, no final das contas, com uma mercadoria produzida pela indústria cultural que fatura muito e que seus lucros são intensificados por meio de estratégias mercadológicas que a retroalimentam, tais como o cinema, os games eletrônicos, o licenciamento de marcas, a criação de blogues, de fanfictions etc. Caso acrescentemos a essas estratégias a possibilidade de inserir os best-sellers seriados como leitura programática em cada uma de quase 2 milhóes de escolas espalhadas pelo mundo, então o resultado redundará em estrondosa expansão do mercado editorial, potencializando ganhos, exacerbando lucros.

$\mathrm{Na}$ avaliação de Adorno \& Horkheimer, como parte do processo de "transposição da arte para a esfera de consumo", a indústria cultural gera no consumidor uma falsa sensação de prazer - posto que nunca o satisfaz obtendo a adesão acrítica aos dispositivos mercadológicos por ela impostos (ADORNO \& HORKHEIMER, 2002, p. 185). Por isso, quando se percebe um ledo professorado se apresentando com atitude náo crítica diante da proposta de uso da literatura de massa para alcançar objetivos educacionais, temos que advertir que o engodo é o inevitável resultado de tal ingenuidade. 
Trata-se de um fenômeno perceptível até mesmo por pessoas desvinculadas de projetos de formação de professores de Língua Portuguesa ou de projetos de formação de leitores. Grande parte destes títulos integra-se a um projeto editorial que previa a publicação seriada dos livros e não é raro ouvirmos relatos de professores envolvidos com as chamadas práticas de leitura ou de ensino de literatura acerca de alunos resistentes ao estudo ou à leitura das chamadas obras canônicas, mas que leem compulsivamente os vários volumes que compóem estas séries.

Os best-sellers a que já aludimos têm sido lidos em escala mundial e há algum tempo figuram entre as obras apontadas como as preferidas por leitores brasileiros em diversas pesquisas, sejam aquelas realizadas por pesquisadores acadêmicos, sejam as produzidas por institutos patrocinados por empresas do mercado editorial. Vale lembrar, a propósito, que as açóes de política econômica e social do governo federal na última década resultaram no trânsito de milhôes de brasileiros para a classe emergente de consumidores, em um país que finalmente vislumbra a distribuição de renda e acesso a bens de consumo, configurando o fenômeno editorial como mais uma oportunidade ao mercado para aumentar o faturamento e os lucros.

Além disso, nunca é demais registrar, os best-sellers em referência foram rapidamente adaptados para o cinema, gerando uma receita de cifras bilionárias, transformando-se em produtos capazes de multiplicar o faturamento por meio da segmentação em exposição em outras plataformas midiáticas, com a venda de produtos licenciados, games e exibição nas TVs a cabo.

O resultado comercial é a criação de um círculo "virtuoso" (do ponto de vista do mercado, claro está), em que a alta vendagem de livros alavanca a bilheteria dos cinemas e o faturamento com o acréscimo de outras mídias e que, por conseguinte, cria um novo público leitor que incrementará a vendagem de mais livros seriados. Ou seja, chega um momento neste processo em que a roda do negócio editorial gira por força própria, independente da qualidade da literatura. Para os interessados na leitura como um mercado a ser expandido, e que garanta um aumento nos lucros das grandes editoras, o fenômeno é aplaudido, com uma forte dose de hipocrisia, como a prova de um despertar da leitura entre adolescentes.

No entanto, a constatação das estratégias de caráter mercadológico não é fator hegemônico para explicar o avanço dos best-sellers seriados sobre os alu- 
nos da Escola e a paulatina aquiescência do professor de língua materna para usá-los em sala de aula. A indústria cultural se apropria de alguns importantes elementos constituintes do zeitgeist e os imprime nos produtos que oferece. Das práticas psicossociais que definem o tempo em que vivemos, o recrudescimento do sagrado tem proporcionado inúmeras oportunidades de expansão editorial, e a indústria cultural não tem deixado de explorar esse nicho.

Cabe aos professores do Ensino Básico compreender as novas configuraçôes do sagrado na sociedade contemporânea, a fim de se inserir neste processo como indivíduo crítico que se apresenta como agente da mesma consciência crítica que se espera alcançar dos leitores em formação.

\section{Pela "plataforma 9 1/2" ou pelo "guarda-roupa": o sagrado como porta de entrada para os best-sellers seriados}

Em Harry Potter e a pedra filosofal, primeiro volume da série produzida por J. R. Rowling, o protagonista atravessa a plataforma 9 1/2 (no original, plataforma 93/4) da King's Cross Station, de Londres, deixando para trás o "mundo dos trouxas", para ingressar no mundo mítico da Escola Hogwarts de magia e feitiçaria. Em O leão, a feiticeira e o guarda-roupa, primeiro volume publicado d'As crônicas de Nárnia, de C. S. Lewis, os quatro irmãos Pevensie fogem dos horrores do bombardeio a Londres, na II Grande Guerra, e descobrem dentro de um guarda-roupa a passagem para o mundo mítico de Nárnia.

Em ambos os casos, por intermédio de novos signos que representam a iniciação ao sagrado (plataforma, guarda-roupa), as personagens se evadem do "mundo real" para experimentarem o "numinoso, o mysterion tremendum et fascinans", expressóes com as quais Rudolf Otto, em texto de 1917, definiu o sagrado: o encontro com o inefável influxo do divino que, concomitantemente, se revela e se encobre, atrai e gera repulsa, se apresenta estranho e natural, desencadeando no sujeito a sucessão de "mistérios" que, ao mesmo tempo, fascinam e aterrorizam (OTTO, 1992, p. 8-15).

A maioria dos best-sellers seriados - e o mesmo se aplica às séries de TV e às franquias cinematográficas - se apodera do sentimento pelo sagrado que vem dominando o ocidente nos últimos 50 anos e apresenta variaçóes do tema ao sedento consumidor da indústria cultural. Os signos do sagrado presentes nessa literatura juvenil, e repercutidos em outros suportes midiáticos, para 
além dos bilhôes que arrecadam, contribuem também para construção de um aparato ideológico conservador e responsável pela manutenção do status quo conveniente para os interesses dos poderes dominantes da sociedade.

Um rápido levantamento acerca das obras mais lidas ou mais vendidas no Brasil nas últimas décadas comprova a preferência pelos textos em que o sagrado é o elemento norteador dessas produçôes. Daí a necessidade de darmos atenção aos contornos do sagrado presentes nestas publicaçôes e suas implicações ideológicas.

Por uma questão metodológica, optamos por buscar tais informaçóes a partir da análise de duas pesquisas sobre os hábitos de leitura no Brasil fora do ambiente escolar. A primeira refere-se ao III Retratos da Leitura no Brasil, publicado em 2012, e patrocinada pelo consórcio liderado pelo Instituto Pró-Livro, cujos fundadores e mantenedores são as editoras de livros. A segunda é a pesquisa de Arnaldo Cortina sobre os livros mais vendidos entre 1966 e 2010, conforme apareceram em listas veiculadas por dois jornais do Brasil, e publicada em 2014 com o título Perfil do leitor brasileiro contemporâneo. As duas pesquisas, vale registrar, apresentam dados coletados ou informaçóes divulgadas por livrarias e editoras de livros, ou seja, por grupos empresariais interessados, antes de qualquer coisa, na venda de livros, o que em muito difere de nossas preocupaçóes no que tange à formação de leitores literários críticos.

Cunha, quando da apresentação das primeiras conclusôes a respeito dos resultados do II Retratos da Leitura no Brasil, a respeito da pesquisa realizada ao longo de 2007, afirma que os resultados mais recentes não diferem muito do relatório do I Retratos da Leitura no Brasil, realizado em 2000, e publicado em livro em 2001, pela Imprensa Oficial do estado de São Paulo: "continuamos lendo pouco, continuamos ligando indefectivelmente leitura e escola" e também que fica cada vez mais sedimentado que "muitas das observaçóes feitas com relação à pesquisa de 2000, seriam feitas aqui, mesmo porque os dados são, na sua maioria, muito parecidos" (CUNHA, 2008, p. 13). Para nós, tal observação serve também para resumir os resultados da pesquisa do III Retratos da Leitura no Brasil, publicado em 2012 - e que passa a ser objeto de nossa análise -, uma vez que poucas alteraçóes foram diagnosticadas.

O que de perto nos chama a atenção nos "Retratos", e que se aplica de modo particular ao nosso estudo, é a constatação de que os títulos em que o 
sagrado se configura o elemento articulador da narrativa são apontados pelos brasileiros como os textos mais lidos ou lembrados pelos brasileiros.

No capítulo 6 do relatório do III Retratos da Leitura no Brasil, intitulado "Preferência dos Leitores" (2012, p. 74-83), encontramos informaçóes sobre os gêneros, os livros e os autores mais apreciados pelos brasileiros, em 2011, e elas confirmam a proeminência do sagrado como o eixo norteador das leituras no Brasil. Na rubrica referente ao "último livro que leu ou está lendo" (2012, p. 83), entre os 22 livros alistados, a série Harry Potter, sem a especificação sobre a qual volume se refere, aparece em $10^{\circ}$, contra o $4^{\circ}$ obtido em 2007, já apresentando o desgaste causado pelo esfriamento da novidade. O primeiro volume da Saga Crepúsculo, produzida por Stephanie Meyer, ocupa o $4^{\circ}$ lugar, enquanto os demais títulos, claramente identificados - Amanhecer, Eclipse e Lua Nova - aparecem em 8º, $14^{\circ}$ e $17^{\circ}$ lugar, respectivamente. O vice-campeão da lista é Ágape, do padre Marcelo Rossi, seguido por A cabana, de Mack Allen Phillips, em 3o lugar. Outros títulos que se destacam são: Violetas na janela, psicografado por Vera Lucia Marinzeck de Carvalho, em 5o lugar; O segredo, roteiro de Rhonda Byrne para o documentário homônimo, caindo de $3^{\circ}$, em 2007, para o $12^{\circ}$ lugar; $O$ almiquista, de Paulo Coelho, demonstra resiliência editorial, mantendo-se na lista, agora em $13^{\circ}$ lugar; A menina que roubava livros, de Markus Zusak, em $19^{\circ}$ lugar; e $O$ monge e o executivo, de James Hunter, em $25^{\circ}$ lugar. No trono do primeiríssimo lugar, inalterável há muitos anos, aparece a Bíblia Sagrada, cujas diversas traduçóes disponíveis no mercado venderam quase 7 milhóes de exemplares naquele ano.

Ainda segundo as informaçóes contidas nos Retratos da Leitura no Brasil, quanto aos 20 "gêneros lidos frequentemente" (2012, p. 80), predominam entre os dez primeiros a Bíblia Sagrada, os livros religiosos, os de autoajuda e os esotéricos. No que se refere aos escritores nacionais mais admirados (2012, p. 81), entre os 25 nomes apontados pelos brasileiros, estão Paulo Coelho, em $3^{\circ}$ lugar; Zíbia Gasparetto, em 90 lugar; Augusto Cury, em 10 lugar; Chico Xavier, em $13^{\circ}$ lugar; Padre Marcelo Rossi, em $14^{\circ}$ lugar; e, finalmente, o Pastor Silas Malafaia, em um emblemático 240 lugar.

A pesquisa de Arnaldo Cortina (2014) sobre os livros mais vendidos entre 1966 e 2010, conforme apareceram em listas veiculadas por dois jornais do Brasil e publicadas com o título Perfil do leitor brasileiro contemporâneo, 
ratifica o diagnóstico sobre a preponderância do sagrado nos gostos de leitura. O mapeamento das principais leituras (ou compras) de livros de ficção e não ficção realizadas pelos brasileiros nas últimas quatro décadas possibilita o estabelecimento do perfil do leitor de textos literários igualmente fora do ambiente escolar.

No trabalho desenvolvido por Cortina - e que aborda um número muito mais expressivo de títulos -, tanto quanto percebemos nos Retratos, verifica-se semelhante predomínio de um corpus que tem algum tipo de vínculo com novas representaçóes do sagrado. Cortina diagnostica nas listas de mais vendidos a preponderância de títulos que ele classifica como "obras de autoajuda" e dedica um capítulo inteiro, intitulado "Encontro do ethos do leitor de autoajuda” (CORTINA, 2014, p. 299-350), para discutir o que considera um fenômeno marcante. São obras de alcance variado, como $O$ alquimista (1988), de Paulo Coelho; O monge e o executivo (1998), de James Hunter; $O$ código Da Vinci (2002), Dan Brown; Comer, rezar, amar (2006), de Elizabeth Gilbert; Nunca desista de seus sonhos (2004), de Augusto Cury.

Após apontar as principais características do gênero e estilo da autoajuda, dividindo-o em subtipos como "autoconhecimento", "misticismo e esoterismo", "individualismo e sexualidade", "mundo dos negócios", "estética corporal", "crenças" e "individualidade e feminilidade", Cortina conclui, destacando os aspectos do que denomina ethos da autoajuda, os quais se aproximam da definição de Otto para o sagrado: individualismo de ascese, ficção simbólica, lendas pessoais, busca da felicidade plena, realizaçóes que proporcionem sentido para a vida (CORTINA, 2014, p. 347-349).

Ao cotejarmos as informaçóes de ambas as pesquisas - e restringindo-nos à década de 2000, para garantir o equilíbrio da comparação -, percebemos a incidência das obras reunidas por Cortina sob as categorias crenças, autoconhecimento - as quais os Retratos denominam religiáo e autoajuda -, misticismo, esoterismo e fantasias (CORTINA, 2014, p. 375-386). O leitor (ou comprador de livros) brasileiro médio dos anos 1960 é formado por uma geração que vivenciou o início do trânsito para a retomada do sagrado na constituição cultural da sociedade, como discutiremos a seguir. Esse leitor migra, gradativamente, para os anos 2010, revelando o interesse por obras com abordagens que tomem o sagrado como eixo norteador ou, pelo menos, que não o prescindam de seu conteúdo. 
O que pretendemos destacar com a análise das informaçóes referidas é a incidência do sagrado nos hábitos de leitura dos brasileiros: são gêneros, autores e obras de caráter explicitamente confessional e dogmático, ao lado de outros de matiz místico, esotérico ou de autoajuda. Em todo caso, tais publicaçôes são marcadas por símbolos subjetivamente pinçados da linguagem religiosa que, independentemente do maior ou menor grau de literalidade, revelam sua aproximação com o sagrado.

A idiossincrasia comum aos autores e às obras que figuram na lista de preferidos pelos leitores brasileiros, segundo os dados publicados no relatório da pesquisa Retratos da leitura no Brasil (2011), reflete o indubitável apego ao sagrado, agora revelado por novas manifestaçóes. Por isso, estamos convencidos de que um estudo sério que pretenda discutir o fenômeno editorial destes best-sellers seriados deve esforçar-se a priori para compreender a maneira como as novas expressóes do sagrado vêm se cristalizando na sociedade contemporânea.

Para a delimitação de um recorte para esta reflexão, mencionamos, em particular, os best-sellers seriados que alcançaram maior divulgação nas diferentes plataformas midiáticas e conquistaram uma parcela considerável do público adolescente de nossas escolas: a série Harry Potter, de Rowling, composta de sete títulos, e cuja vendagem se estima que tenha ultrapassado meio bilhão de exemplares; e a série Crepúsculo, de Meyer, composta de quatro títulos e com quase 200 milhóes de cópias vendidas. Uma vez que de modo recorrente as autoras Rowling e Meyer têm apontado os best-sellers seriados As crônicas de Nárnia, de Lewis, e $O$ senhor dos anéis, de Tolkien, como os paradigmas que nortearam suas produçóes, torna-se necessária inclusão destes títulos para o devido cotejo.

A lista poderia ser acrescida de outros tantos romances. Entretanto, basta-nos as duas bem-sucedidas duplas de autores para a pretensiosa tarefa (ou seria saga?) deste artigo: apontar e discutir o uso recorrente de signos extraídos do sagrado em obras que disputam a preferência de leitura entre os brasileiros e avaliar a maneira como tais influências agem sobre os professores de Língua Portuguesa, quando das escolhas de obras literárias com as quais pretendem formar leitores literários no Brasil. Para auxiliar nessa reflexão, é importante discutir a maneira como o retorno do sagrado à cultura ocidental se estabeleceu. 


\section{Novas representações do velho sentimento do sagrado}

Até o fim da primeira metade do século XX, quando surgem as obras de Lewis e Tolkien, a sociedade ocidental tentou afastar o sagrado da construção e da interpretação do mundo dos acontecimentos cotidianos. Na avaliação de Alves, "a ciência e a tecnologia avançaram triunfalmente, construindo um mundo em que Deus não era necessário como hipótese de trabalho" (ALVES, 1984 , p. 8). No lugar do sagrado colocou-se a ciência para reger sua vida, dando-lhe símbolos que a explicassem. Daí, não causa nenhum estranhamento o fato de as obras e Lewis e Tolkien terem sido recebidas por seus coetâneos com grande desconforto, gerando uma reação negativa perante a crítica literária e também nos demais segmentos da sociedade. Umberto Eco registra que se $O$ senhor dos anéis, na época em foi lançado, fosse objeto de leitura programática nos colleges, os estudantes iriam às ruas protestar contra tal "medievalidade supersticiosa e atrasada" (ECO, 1984, p. 111). Os leitores desse período preferiam, sem dúvida, as descriçóes tecnológicas presentes na obra de Isaac Asimov, autor de ficção científica apreciada por jovens e adolescentes nos anos 1950, como representação mais próxima ao espírito daquela época.

Os sociólogos dessa geração consideravam a situação contemporânea da religiáo como de secularização da cultura moderna, de afastamento do sobrenatural no mundo. Eles passaram a cunhar formulaçóes como "Deus está morto" ou "era pós-cristâ" para referir-se a este período. Peter Berger comenta que, como reflexo desse contexto de dessacralização, em 1962, os pesquisadores Kahn e Wiener, ao resenharem um estudo que pretendia projetar os próximos 30 anos daquele século, praticamente omitem o papel da religião no mundo finissecular, na presunção de que a sociedade caminhava para a eliminação total do sagrado, do mítico, do numinoso (BERGER, 1994, p. 42-43).

Todavia, as últimas décadas do século XX permitem-nos constatar que o fenômeno social que efetivamente se constituiu foi exatamente o oposto: a sociedade desenvolveu-se em direção ao retorno da espiritualidade, por meio do resgate de antigas tradiçóes religiosas e do estabelecimento de novas formas do sagrado. Com o término da II Grande Guerra, a segunda metade do século XX acentua seu sentimento de náusea para com a existência humana e constata a falta de sentido para a vida em face às atrocidades bélicas aprimoradas 
pela tecnologia. O final dos anos 60 experimenta um fenômeno inimaginável até então: uma onda de valorização do sagrado começa a refletir-se em diversas expressóes sociais, da arte à cultura, da política cotidiana à própria experiência religiosa eclesial.

Um dos primeiros a perceber o sopro deste movimento foi Peter Berger. Ele publica, em 1969, nos Estados Unidos, uma obra cujo subtítulo apontava os novos ventos do fenômeno: Rumor dos anjos: a sociedade moderna e a redescoberta do sobrenatural. Em sua avaliação, "há algumas razões para se pensar que bolsões de religião sobrenaturalista sobreviverão dentro da sociedade. É um prognóstico bastante razoável de que num mundo "livre de surpresas" a tendência geral de secularização continuará". No capítulo com o sugestivo título "A suposta morte do sobrenatural", ele antecipa peremptório: "uma impressionante redescoberta do sobrenatural, nas dimensóes de um fenômeno de massa, não está nos livros. Ao mesmo tempo, áreas de sobrenaturalismo continuarão a se encravar na cultura secularizada” (BERGER, 1994, p. 55)

No fim dos anos 1970, em artigo intitulado "O sagrado não é uma moda”, Eco diagnosticou as evidências do novo espírito de época, perceptíveis em diversas formas de expressão da arte: "a humanidade está vivendo um novo despertar do sagrado” (ECO, 1984, p. 110-116). Vale lembrar que por todo o século XX, e mais intensamente após o fim da Segunda Guerra Mundial, os pensadores proclamavam a velha concepção difundida pelo Iluminismo de que o homem finalmente se livrara do atraso do sentimento religioso, posto que vivenciava uma nova era de vida orientada pela razáo, pela ciência.

Eco argumenta a partir da comparação entre o Super-Homem dos "gibis” dos anos 1930 e o Super-Homem cinematográfico do fim dos anos 1970, destacando que a diferença estava na essência dos personagens: enquanto o personagem dos gibis nada tinha de místico ou misterioso, pois tudo se explicava cientificamente, desde os superpoderes até a memória prodigiosa, o Super-Homem do cinema, por sua vez, era carregado de material simbólico religioso, ora assemelhando-se a um Moisés colocado em um "rio Nilo sideral", ora parecendo uma "Joana d'Arc habitada por vozes do além" (ECO, 1984, p. 111). Para o articulista, tal constatação se somaria a um quadro social que caracterizaria o último quartel do milênio: "uma série de fenômenos mais profundos e complexos que parecem sublinhar todos uma mesma tendência: a volta do pensamento religioso" (ECO, 1984, p. 112). 
O retorno do pensamento religioso, conforme foi apontado por Eco, como tendência que se confirmou posteriormente, explica-se em face ao conceito de sagrado no mesmo sentido como lemos, por exemplo, em Ludwig Feuerbach, Rudolf Otto, Mircea Eliade e Rubem Alves: O homem sente que é infinito, capaz de querer de modo ilimitado, de querer tudo. Mas percebe não ser capaz de realizar o que deseja, e então precisa "imaginar-se Outro (que possua em medida optimal o que ele deseja) e a quem se delegue a tarefa de preencher a fratura entre o que se quer e o que se pode" (ECO, 1984, p. 112).

A propósito, quando Giuseppe Laterza, em 1994, elaborou um projeto com vistas à ampliação do Anuário Filosófico Italiano, criando um anuário europeu, chamou Gianni Vattimo e Jacques Derrida para organizarem um seminário que pensasse a Europa no final do século XX e tecesse projeçóes para o próximo milênio. Ambos, sem trocarem impressóes pessoais entre si - e com perspectivas antagônicas às previsóes de Kahn e Wiener, nos anos 1960, sobre o desaparecimento do sagrado na cultura ocidental -, propuseram o mesmo tema para discussão: a religião e o dito retorno do sentimento religioso, cujos extratos foram reunidos em A Religião: o seminário de Capri (DERRIDA \& VATTIMO, 2000, p. 8).

No entanto, mais que registar o retorno do sagrado à cultura ocidental, Eco cria ser necessário distinguir entre a religiosidade institucional - em crise, como se percebia ao verificar as igrejas esvaziadas - e o sentido do sagrado que se manifestava por meio de formas alternativas. Na perspectiva dele, as manifestaçôes do sagrado na contemporaneidade dão-se de duas maneiras. Por um lado, aqueles que já revelavam algum tipo de religiosidade, geralmente de viés institucional e tradicional, renovaram-na mediante uma intensa participação em movimentos cristáos conservadores, papistas, neopentecostais, milenaristas e glossolálicos; e no Islamismo, intensificaram-na através do estabelecimento de governos de visão teocrática e da valorização das práticas mais radicais. Por outro lado, aqueles que antes se perfilavam entre ateus e agnósticos, agora parecem se encontrar na leitura de clássicos contemplativos, na astrologia, na cabala, nas obras de autoconhecimento, nas fantasias místicas, entre outros. Em ambos os casos, configura-se o estabelecimento de grupos sociais a que o pensador italiano chamou de "uma nova idade média de místicos leigos".

$\mathrm{Na}$ avaliação de Eco, portanto, o despertar do sagrado é alimentado por duas crises finisseculares de compleiçóes filosóficas antagônicas: a primeira diz respeito à ideologia positivista-tecnológica de um capitalismo otimista com o 
progresso da sociedade e "que queria construir um mundo melhor com o auxílio da ciência"; a segunda tem a ver com o materialismo-histórico protagonizado pelo comunismo, "que queria construir uma sociedade perfeita por meio da intervenção revolucionária” (ECO, 1984, p.113). Ambas frustram a humanidade no seu anseio de construir utopias com as quais sonharam; ou, para usar a expressão consagrada pelos autores alistados anteriormente, o desejo de ser Outro, ou mesmo, o desejo incontido de projetar-se em alguma forma escapista de alteridade. Em outros termos e em linguagem "harrypotteriana", a retomada do sagrado nesse tipo de literatura evidencia o desejo de embarcar na Plataforma $91 / 2$ com a naturalidade de quem táo somente empurra seu carrinho de bagagem no mundo real da King's Cross Station, de Londres; ou, no mesmo sentido, mas em linguagem "narniana”, seria a certeza de poder deixar o mundo trivial, representado pelo quarto de dormir de adolescentes comuns, ao passar pela porta do Guarda-roupa que leva ao encontro com o fantástico mundo do sagrado.

Não obstante capitalismo e comunismo serem sistemas político-econômicos tão distintos, na essência - qual irmãos gêmeos em conflito -, estavam imbuídos da mesma tarefa: "preencher a fratura entre o que se quer e o que se pode". O fracasso de ambos predispôs o Homem a um retorno ao pensamento religioso como resposta a estes desejos irrealizados. Em suma, como forma de reagir ao sentimento de irrealizaçáo do desejo coletivo, quem acreditava em manifestaçooes metafísicas, transcendentais (cristâs ou não), passa a crer ainda mais e de forma mais tradicional; e quem não acreditava no mundo metafísico (ateus de diversas categorias) inventa formas alternativas de revelar a sua "nova religiosidade". Foi nesse contexto de busca de alternativas que a arte - incluindo aí, a literatura de massa produzida pela indústria cultural - passou a refletir novas expressóes do sagrado, resultando na apreciação desmesurada aos best-sellers seriados a que vimos nos referindo.

Quando Umberto Eco propôs a tese da retomada do sagrado a partir de novas formas de expressão, em 1979, ele não pretendia afirmar o fim da crise de frequência aos serviços religiosos das Igrejas Cristãs históricas - que na minha avaliação, e sob uma perspectiva 35 anos depois, se reverteu - mas, sim, que o fenômeno do retorno ao sagrado se concretizava em "novas formas pessoais de religiosidade [...] e que dizem respeito a guinadas conservadoras" (ECO, 1984, 115), sobretudo na produção da arte inserida nos interesses mercadológicos da indústria cultural. 


\section{Novos velhos signos do sagrado nos best-sellers seriados}

Em meio ao recrudescimento deste tipo de sentimento religioso que marca o período, conscientemente ou não, mas certamente refletindo este espírito de época, é retomado o interesse pela série As crônicas de Nárnia, de Lewis, e de $O$ senhor dos anéis, de Tolkien, ambas adaptadas para o formato sequencial cinematográfico, refletindo o espírito da nova religiosidade. $\mathrm{O}$ sagrado, que nunca foi uma moda que vai e volta, paradoxalmente "retorna" no último quartel do século XX, fortalece-se e manifesta-se através de formas alternativas no início do século XXI, com as séries literárias Harry Potter, de Rowling, e A saga Crepúsculo, de Meyer, ambas também transformadas em sequências no cinema.

Os elementos do sagrado que predominam nessas obras também se fazem presentes em outros textos literários voltados para o público juvenil, e com os quais alguns professores e pesquisadores propóem o trabalho com a formação de leitores nas escolas. Os volumes das séries Harry Potter e Crepúsculo, bem como os das séries As crônicas de Nárnia e $O$ senhor dos anéis, estão repletos de signos religiosos, extraídos do mundo do sagrado. Nelas, há uma profusão de personagens oriundos das velhas lendas, superstiçóes e fantasias, que amiúde frequentaram os velhos contos de fadas, do mundo do maravilhoso e das histórias fantásticas: são bruxos, feiticeiros, magos, duendes, monópodes, dríades, vampiros, dragôes e lobisomens; são elfos, grifos, sátiros, faunos, centauros, hipogrifos e outros animais falantes; são anjos, demônios, filhos de Adão e filhos de Eva. Mas são, também, espaços provenientes do velho mundo do sagrado, tais como os castelos de encantamentos, as escolas de magia, as távolas ritualísticas de mistérios, os paraísos terrestres, os templos, as confrarias, as igrejas e os cemitérios.

Em meio a esses personagens e espaços místicos - que em nada diferem do conto maravilhoso ou da literatura fantástica -, os personagens do mundo trivial interagem, após o brevíssimo tempo necessário para assimilar o estranhamento, com enorme naturalidade e desenvoltura, posto que as energias devem ser canalizadas para alguma missão geralmente de natureza soteriológica universal.

Em termos gerais, os leitores dos referidos best-sellers, atendendo ao senso comum de seu tempo, envolvem-se no prazeroso jogo imaginativo que tais leituras lhes proporcionam e, identificando-se com seus personagens, deixam-se transmutar de sua tediosa realidade material para as dinâmicas realidades do mundo sagrado. Para alcançar a fidelização do leitor, as narrativas aplicam 
transmutaçóes recorrentes: do meio dos familiares ranzinzas e das figuras triviais, as personagens são retiradas para o convívio com bruxos, elfos, duendes e outras criaturas sobrenaturais; do meio da rotina tediosa da sociedade convencional, jovens e adolescentes, outrora sem brilho ou relevância, se tornam protagonistas de mundos exóticos, nos quais são convocados para missóes desafiadoras; em meio aos graves perigos e aos conflitos aparentemente insolúveis, a intervenção sobre-humana dá conta de providenciar intrincados escapes; em meio aos perigos extremos, a segurança é depositada na proteção de uma força externa poderosa responsável por reequilibrar as açóes humanas; da irrelevância social em que vivem, jovens e adolescentes são levados a assumir papéis fundamentais para a salvação do mundo, guarnecendo suas missóes de um caráter soteriológico coerente com as idiossincrasias do mundo sagrado, e com cujo envolvimento os leitores imprimem novos sentidos à vida cotidiana.

Até aí, repetimos, nada que já não se tenha sido visto nas novelas de cavalaria medievais, nas demandas do Santo Graal; nada que já não tenha sido explorado pelo gênero terror do Romantismo oitocentista. Para além dos recursos estéticos de linguagem que constituem as opçóes de enredo, de cronotopos e de construção de personagens - e que, como afirma o autor do Eclesiastes, já foi novo em séculos anteriores - o que chama a atenção nessas "novas manifestaçôes do sagrado" dos best-sellers seriados são as marcas de crasso e ingênuo conservadorismo que visam a galvanizar o comportamento da atual geração de adolescentes: a salvação do mundo por meio da intervenção sobrenatural, coadjuvada pelas açóes humanas; a crença no poder de regeneração do amor sobre personalidades antes reprováveis; a expectativa inexorável da vitória do bem contra o mal e a inegociável certeza da recompensa final do bem em contraste com o castigo do mal; a possibilidade, quando viável, da regeneração do mal ou sua recuperação espiritual; a idealização dos sentimentos de companheirismo e amizade; a presença das relaçóes humanas tradicionais de família; o espírito individualista e altamente competitivo de grupos ou classes; a valorização de antigos tabus, como a virgindade e o sexo primordialmente reservado para a procriação.

O neoconservadorismo aparece vitorioso nas novas manifestaçóes do sagrado presentes na literatura juvenil dos best-sellers seriados. Um capítulo importante dessa pesquisa deveria averiguar, com a profundidade que o tema exige, que espécie de mundo brota dessas narrativas e que paradigmas compor- 
tamentais eles apresentam para os jovens e adolescentes dessa geração de consumidores de literatura de massa. O resultado possivelmente revelaria um modelo de sociedade conservadora, com valores parecidos com os da geração de seus avôs - e contra os quais aquela geração lutou para derrubá-los ou transformá-los -; uma sociedade firmada em bases mais tradicionais, recrudescidas de conservadorismo, mas que se pretende inovadora, paradoxalmente, quando utiliza velhos signos de um "renovado" sagrado. Como dissemos anteriormente, basta observar como as quatro obras seriadas com que vimos lidando se abstêm de lidar com temas como as injustiças coletivas ou as desigualdades sociais, presentes tanto nas sociedades dos anos 1950, quanto dos anos 2000.

\section{Considerações finais}

O fenômeno da retomada pela leitura dos best-sellers seriados como mercadoria tem se consolidado no mundo e no Brasil e reflete o fortalecimento da sociedade de consumo deste início do século XXI também no campo das artes. Trata-se do surgimento de um novo (?) leitor - ou, talvez em temos mais adequados, da formação de um novo nicho mercadológico - para quem a leitura deixa de exercer suas principais funçóes sociais e passa a limitar-se ao papel de entretenimento dentro do espírito da época. Reflete, por conseguinte, como ficou evidenciado na pesquisa realizada pelos Retratos da leitura no Brasil (2012), que a formação de leitores vem se descolando da escola e passa por estratégias que captam [ou criam] desejos de consumo. Neste sentido, estou convencido de que o estudo do fenômeno precisa ater-se, com muito cuidado, às novas manifestaçóes do sagrado na sociedade contemporânea.

Do ponto de vista dos educadores, é importante refletir acerca da íntima relação feita pelo brasileiro (e não só ele) entre leitura e escola: ela é tanto legítima quanto necessária - enquanto somos estudantes. O problema é acharmos que a leitura só tem a ver com a vida estudantil. Aquela ideia de "desescolarizar" a leitura, que esteve em moda e conseguiu adeptos importantes na década de 1990, perdeu força e não pode confundir-se com o desejo legítimo de que a leitura extrapole os muros e os tempos da escola. Acredito firmemente que, se a leitura não pode ser uma funçáo unicamente da escola, cabe a ela, sim, formar e desenvolver o leitor para além e para depois da alfabetização e do período da vida escolar. Por outro lado, as pressóes uniformizadoras, em geral voltadas para o consumo 
ou para a não reflexão sobre problemas estéticos ou sociais, exercidas pela mídia, exigem a ação do professor no trabalho de construção do leitor crítico.

O estudo destes best-sellers consumidos por jovens e adolescentes do início do século XXI ainda precisa desenvolver-se a fim de responder questôes como o impacto deles na configuração de uma geração ou vice-versa. Cada vez mais, encontramos alunos dos cursos de Letras - responsáveis no futuro pela formação de leitores literários -, que vieram da experiência adolescente de leitura contumaz destas obras e se apresentam confusos acerca do posicionamento perante o fenômeno. Enfim, são visíveis as deformaçôes na capacidade crítica destes leitores e cada vez mais crescente a construção do mito de que tais leituras servem como porta de entrada para as leituras de obras da canonicidade literária.

\section{Referências}

ADORNO, Theodor \& HORKHEIMER, Max. A indústria cultural: o iluminismo como mistificação de massas. pp. 169 a 214. In: LIMA, Luiz Costa. Teoria da cultura de massa. São Paulo: Paz e Terra, 2002. Disponível em https://nupese. fe.ufg.br/up/208/o/ADORNO.pdf?1349568504. Acessado em 15.09.2015

ALVES, Rubem. O que é religião? São Paulo: Brasiliense, 1984.

BERGER, Peter. Rumor de anjos: a sociedade moderna e a redescoberta do sobrenatural (Trad. Waldemar Boff e Jaime Clasen). Petrópolis: Vozes, 1996.

CHIAPPINI, Lígia. Reinvenção da catedral: língua, literatura, comunicação: novas tecnologias e políticas de ensino. Sáo Paulo: Cortez, 2005.

COMPAGNON, Antoine. O demônio da teoria: literatura e senso comum. Trad. Cleonice Mourão, Consuelo Santiago. Belo Horizonte: Editora da UFMG, 2001.

CORTINA, Arnaldo. Perfil do leitor brasileiro contemporâneo: os livros mais vendidos no Brasil de 1966 a 2010. Campinas, SP: Mercado de Letras, 2014.

CUNHA, Maria Antonieta. Acesso à leitura no Brasil: considerações a partir da Pesquisa. In AMORIM, Galeno. II Retratos da Leitura no Brasil. São Paulo: Instituto Pró-Livro, 2008. pp. 12-17. Acessado em 8 de Setembro de 2015. Disponível em: http://www.abrelivros.org.br/home/images/abrelivros/arquivos/Retratos_da_Leitura_no_Brasil_2008.pdf. Acessado em 13.9.2015.

DERRIDA, Jacques \& VATTIMO, Gianni (org.). A Religião: o seminário de Capri. Trad. Guilherme Teixeira. São Paulo: Estação Liberdade, 2000. 
EAGLETON, Terry. Marxismo e crítica literária. Trad. Antonio Sousa Ribeiro. Porto: Afrontamento, 1978.

ECO, Umberto. Viagem na irrealidade cotidiana. Trad. Aurora Bernardini e Homero Andrade. Rio de Janeiro: Nova Fronteira, 1984.

JOACHIM, Sébastien. Aspectos da Leitura (Org. Anco Márcio Tenório Vieira, Ângela Paiva Dionisio). Recife: PPGL-UFPE, 2010.

KOTHE, Flávio. A narrativa trivial. Brasília: editora UnB, 2007.

OTTO, Rudolf. O sagrado. Lisboa: Edições 70, 1992.

RICOUER, Paul. Ideologia e utopia. Trad. Tereza Perez. Lisboa: Ediçóes 70, 1999.

SODRÉ, Muniz. Teoria da literatura de massa. Rio de Janeiro: Tempo Brasileiro, 1978.

\title{
THE FORMATION OF READERS IN THE ERA OF ITS "SACREDNESS": IT WOULD BE THE SACRED THE CAUSE OF FASCINATION WITH CONTEMPORARY BESTSELLERS?
}

\begin{abstract}
What explain the great appreciation by mass literature, as the bestseller Harry Potter or The Twilight Saga? We can use the mass literature to form readers in the school, or we must use only canonical literature? Finally, the more important discussion in this article: the sacred would be an enhancer element to explain the appreciation by these works and how would must the teachers debate this theme with their students?
\end{abstract}

KEYWORDS: formation of reader; mass literature; sacred

Recebido em: 01/10/2015

Aprovado em: 25/01/2016 